smaller only in autistic patients. (Hashimoto $\mathrm{T}$ et al. Magnetic resonance imaging of the brain structures in the posterior fossa in retarded autistic children. Acta Paediatr Dec 1992; 1 1: 1030-4). (Respond: T Hashimoto MD, Department of Pediatrics, University of Tokushima School of Medicine, 18-15 Kuramoto-cho 3, Tokushima 770, Japan).

COMMENT. The authors suggest that in autism a specific brain stem lesion may be masked by a lesion of mental retardation. Further examination of autistic children with a normal IQ is planned.

\title{
FRAGILE X FEMALES AND PSYCHIATRIC DISORDERS
}

Psychiatric and developmental difficulties in 17 young females with the fragile $X$ mutation were compared with a non-fragile $X$ female group in a controlled study reported from the Department of Psychiatry, Division of Child and Adolescent Psychiatry, The Johns Hopkins University School of Medicine and the Kennedy Institute, Baltimore, MD. Fragile X females showed a greater frequency of avoidant, mood, and stereotypy/habit disorders than controls. They were more withdrawn and depressed and showed greater deficits in interpersonal socialization skills. The frequency of ADHD was not increased. Seven of the subjects in each group had IQs below 70. Size of DNA insertion was correlated with IQ attention problems, and anxiety/withdrawal symptoms. (Freund LS, Reiss AL, Abrams MT. Psychiatric disorders associated with fragile $X$ in the young female. Pediatrics Feb 1993; 91: 321-329). (Reprints: Dr LS Freund, Behavioral Genetics Ctr, 550 N Broadway, Rm 507, Baltimore, MD 21205).

COMMENT. Contrary to previous reports, the fragile $\mathrm{X}$ females did not show a greater frequency of ADHD or undifferentiated attention deficit. The authors comment that the control group may have been biased for attention problems. Similar to other studies, 35\% of fragile X females exhibited repetitive behaviors, compared to none of the controls. The absence of retardation among fragile $X$ females does not protect from psychiatric and social difficulties. Sisters of fragile X males should be tested genetically by DNA analysis to provide early diagnosis and allow therapeutic intervention.

\section{ENVIRONMENTAL TOXIC DISORDERS}

\section{PRENATAL PCB EXPOSURE AND COGNITIVE DEVELOPMENT}

IQ scores of 118 Taiwanese children who had been exposed prenatally to high levels of heat-degraded polychlorinated phenyls (PCBs) in contaminated rice oil and compared with controls are reported from the National Cheng Kung University Medical College, Tainan, Taiwan, and the National Institute of Environmental Health Sciences, Research Triangle Park, North Carolina. 
Exposed children scored 5 points lower on the Chinese versions of the Stanford-Binet and WISC-R at ages $4-5$ and $6-7$ years, respectively. Children born up to 6 years after maternal exposure and tested at 6 and 7 years of age were as affected as those born within a year after exposure. (Chen Y-CJ, Rogan WJ et al. Cognitive development of Yu-Cheng ("oil disease") children prenatally exposed to heat-degraded PCBs. IAMA Dec 9 1993; 268: 3213-3218). (Reprints: Dr Chen, Department of Psychiatry, National Cheng Kung University Medical College, 138 Sheng Li Rd, Tainan 70428, Taiwan, Republic of China).

COMMENT. In the US children born to women who routinely consumed Lake Michigan sportfish had poorer short-term memory function on both verbal and quantitative tests in a dose-dependent fashion (Jacobson JL et al. Effects of in utero exposure to polychlorinated biphenyls and related contaminants on cognitive functioning in young children LPediatr 1990; 116: 38). Rogan WJ, an author of the Taiwan report, has written several articles on the in utero effects of PCBs on child development, a hazard that requires effective governmental disposal. (Also see Environmental Poisons in our Food, Millichap JG, Chicago, PNB Publ, 1993, 271 pp).

\section{LEAD EXPOSURE AND MOTOR DEVELOPMENT}

The neuromotor assessment of 245 six-year-old urban inner-city children enrolled in the Cincinnati Lead Study is reported from the Departments of Environmental Health and Pediatrics, University of Cincinnati College of Medicine, and the Children's Hospital Medical Center, Cincinnati, OH. Quarterly measures of blood lead and development since birth showed that neonatal, but not prenatal blood lead levels were associated with impaired coordination, hand speed and dexterity. Postnatal blood lead levels were associated with similar impairments of coordination, and poorer scores on visual-motor control. Low to moderate lead exposure is associated with moderate deficits in gross and especially fine-motor development. Blood lead levels peaked at 2 years of age and then slowly declined; 87 children (35\%) had levels of $25 \mathrm{mcg} / \mathrm{dL}$ or greater during the first 5 years of life, while 195 (80\%) had at least one level at or above $15 \mathrm{mcg} / \mathrm{dL}$ during this period. Only $5 \%$ were chelated therapeutically. (Dietrich KN, Berger OG, Succop PA. Lead exposure and the motor developmental status of urban six-year-old children in the Cincinnati prospective study. Pediatrics Feb 1993; 91: 301-307). (Reprints: Dr Dietrich, University of Cincinnati College of Medicine, Dept of Environmental Health, Cincinnati, OH 45267).

COMMENT. The cerebellum is particularly sensitive to lead intoxication in neonatal rats, and glial cell development and brain histogenesis are affected. In children of low socioeconomic status, motor development 